\title{
MOBILE INDOOR LASER SCANNING FOR 3D STRATA REGISTRATION PURPOSES BASED ON INDOORGML
}

\author{
Mohd Nizar Hashim ${ }^{1,2}$, Muhammad Imzan Hassan ${ }^{1}$, Alias Abdul Rahman ${ }^{1}$ \\ ${ }^{1}$ 3D GIS Research lab, Faculty of Built Environment and Surveying, Universiti Teknologi Malaysia (UTM) \\ mnhpiko@gmail.com,imzan@utm.my, alias@utm.my \\ ${ }^{2}$ Politeknik Kuching Sarawak, km22, Jalan Matang, 93050, Kuching Sarawak. -mnhpiko@ gmail.com
}

KEY WORDS: 3D registration, 3D strata, 3D model

\begin{abstract}
:
In Malaysia, the current 2D cadastre system is regularly updated by the National Mapping Agency (NMA) and Land Offices (LO). However, this 2D information may not be able to serve complex situations. The 3D strata acquisition and 3D modelling are important for strata title to manage the Right, Restriction and Responsibility (RRRs). This means there is a need for the system to be extended into 3D cadastre environment. One of the data acquisition techniques such as LiDAR from Mobile Laser Scanning (MLS) could be utilised to solve the problem. This research also discusses the $3 \mathrm{D}$ geospatial objects generated from the captured pointclouds, modelled in SketchUp and transformed into IndoorGML. In this study, Web application is developed as a platform for generating an integrated XML-IndoorGML schema. Thus, this research contributes on 3D strata modelling especially for the development of 3D strata registration in Malaysia.
\end{abstract}

\section{INTRODUCTION}

Strata Rapid development of a country created more spaces for industrial and residential buildings land usages. This is indirectly inspiring multilayer building (strata) especially for the development of residential properties such as flat, apartments, condominiums and others. Development of these strata unit is related to strata title plans. This strata title process involves many parties such as Pejabat Tanah Galian (PTG), Surveyors and Jabatan Ukur dan Pemetaan Malaysia (JUPEM). Currently development strata title is done in $3 \mathrm{D}$ and to support this process $3 \mathrm{D}$ strata registration is proposed for future.

There are various advantages of using 3D strata registration including good accessibility to the legal status of stratified property, digital drawing storage of 3D representation (instead of hard copy in document of title) and access of 3D spatial information through unique parcel identifier of the surface parcel (computerisation instead of manually search for the associated hard copies), and enhancing to include the snapshots of the property from the exterior and interior, or the panorama images.

Strata title is an ownership designed for multi-level apartment blocks and subdivisions with shared areas. As expressed in the National Land Code (1965), the 'strata' term refers to building has multiple levels. Strata title was first presented in New South Wales on 1961, to manage with authorised ownership of building apartment blocks.

The urbanization has encouraging to the development and transformation of pattern in property ownership. According to Noh (2012), the demands of high buildings are increasing and they have been built to offer different types of property tenure other than landed property. The needs for strata title is growing rapidly as the buildings with more than one floor where every floor has many lots are built. It led to the beginning of a new law which is the Strata Titles Act 1985 (STA).
Previously, Strata Titles Act 1985 formation of subdivision of the building was provided in the National Land Code (NLC) 1965. There were cons and flaws discovered in the enactment before in relations and terms of technical and also legal requirements. Therefore a new, better and improved legal structure is applied which finally leads to the STA.

STA 1985 is an act to assist the subdivision of buildings in lots or parcels. This act is made of a few applications such as registration, subdivision, and issuance of strata title outline as known as "Strata Title Board". The STA is under the supervision of the Federal Department of Land and Mines (JKPTG) which is under the Ministry of Water, Land and Natural Resources Malaysia (KATS). STA was implemented and enforced starting June, 1985. All types of title applications for the high-rise buildings parcel can be made under the provisions of NLC 1965 before this act was held.

Section 2 discusses on problem statement. Methodology discuss in section 3. Section 4 describes the integrated XMLIndoorGml. Conclusion and future work will be discussed in section 5 .

\section{PROBLEM STATEMENT}

The idea of having 3D database for the cadastral system has been discussed and elaborated for a good and efficient management in Malaysia (Hassan, 2017). As reported by Stoter and Oosterom (2006), the 3D development was approach in other domains such as 3D GIS (Geographical Information Systems) and it will make a 3D cadastral realisable. In Malaysia, the current 2D cadastre system is commonly updated by the National Mapping Agency (NMA), i.e. the Department of Survey and Mapping Malaysia (JUPEM). However, this 2D information may not be able to serve complex situations. Thus, there is a need for the system to be extended into $3 \mathrm{D}$ cadastre environment. 
The authority utilises traditional technique and other existing floor plans for strata modelling (Isa et al., 2018). However, the existing technique (i.e. traditional building survey) is laborious and time consuming for $3 \mathrm{D}$ objects modelling purposes. Other than that, it is difficult to get a proper floor plan depending on the building age (old and existing building), developers, local authorities and others (Hashim et al., 2018). One of the methods is to use Light Detection And Ranging (LiDAR) data to solve the problem.

LiDAR data has been captured and used in various places including in Malaysia. This data has been collected by national and private data providers for various mapping tasks including 3D city modelling, 3D cadastre and strata (Buyuksalih and Bayburt, 2017; Abdul-Rahman, 2016). The data offers several advantages especially its high accuracy despite the high costs and huge data volume. The 3D geospatial objects could be produced from the captured point-clouds and there are many work been initiated by the related agencies for 3D geoinformation. The national mapping agency tries to make use of LiDAR datasets (airborne and terrestrial) for 3D cadastre and recently the authority has deployed indoor laser scanning technique for strata purposes. Therefore, this piece of work suggest to utilise one of the indoor modelling standards, namely IndoorGML for representing 3D indoor features.

IndoorGML has been discussed much at international level. This review includes multi-storey buildings as well as condominiums (Tekavec and Lisec, 2018). With Extensible Markup Language (XML) based data formats (Ilku and Tamas, 2018), this model needs to fit with the existing framework in Malaysia. According to Alattas et al (2018), since XML is a data exchange format which is widely used in the Web, an application with generating database should be developed to support the integrated IndoorGML data. On the other hand, the indoor laser scanned data could be utilised for 3D strata modelling, thus it forms major experiment in this research. The research also attempts to explore the aspect of accuracy of the generated rooms geometry and intends to briefly incorporate the 3D strata model and 3D strata registration.

\section{METHODOLOGY}

This research is divided into five main phases. Figure 1 shows the general flows of the methodology and started with phase of preliminary study which includes planning, literature review, state the aims, state the objectives and scope.

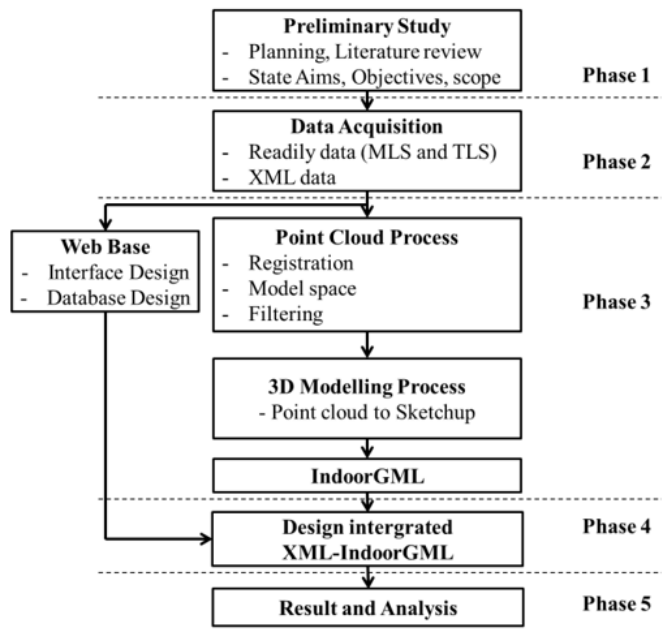

Figure 1. General flows of the methodology

Phase 2 involves data acquisition while Phase 3 involves the point-clouds processing, 3D modelling, IndoorGML and the development of the web base. Phase 4 describes the design integrated XML-IndoorGML and result and analysis will be discussed in phase 5 .

\subsection{Data acquisition}

Based on the preliminary study, there are two types of data needed to be accomplished in this research. The current development of 3D strata model and the current standard XML are required for this study. Figures 2 show the data acquisition techniques for this study.

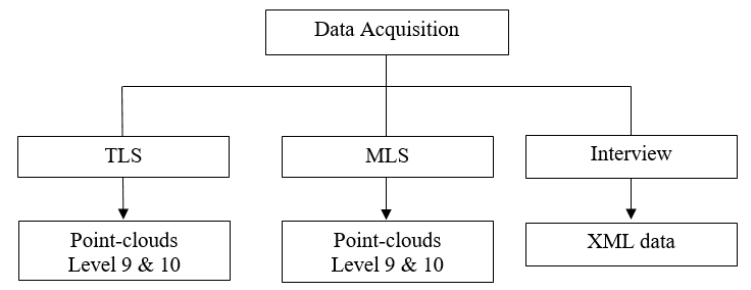

Figure 2. Data acquisition techniques

JUPEM has been providing the data point-clouds using TLS and MLS. The data provided are data for floor level 9 and 10 of their building at Jalan Semarak. For TLS the data was captured by Topcon - C10 while MLS is using Reigl product. Besides, several series of interview have been carried out for further explanation on the problems and the system used by JUPEM.

\subsection{Point Cloud Processing}

Terrestrial Laser Scanning (TLS) data provides images and points cloud. This data is processed using the Cyclone and SketchUp software. In Cyclone point-clouds data must be registered, then a model space is created and filtered before converting it into suitable format such as *.las, *.ptx, *.pts and others.

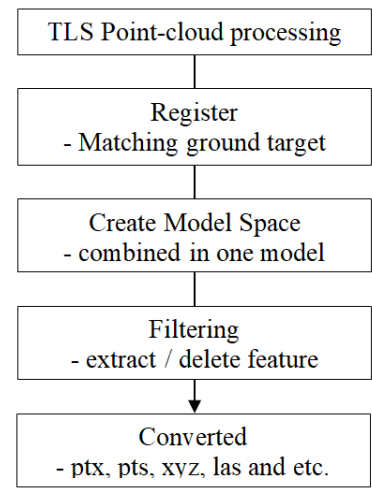

Figure 3. Flows of the processing point-clouds

Register point-clouds is also known as point matching (use target on ground as a reference point), is the process of finding a spatial transformation that aligns two or more point set. The purpose of registration is to merge multiple data sets into one model space and readily to filter. Filtering process is to extract feature from raw point-clouds dataset. After filtering is completed, point-clouds data will be converted into *.pts format. 


\subsection{D modelling process}

LiDAR data processing requires high-end computing specifications due to a huge number of data volume (pointclouds). Figure 4 shows the flow method from point-clouds to 3D modelling processes. One of the tools for TLS data processing is Cyclone (from Leica). On the other hand, $Q T$ Modeler is meant for MLS datasets. Then, the data in *.pts format could be transferred for 3D modelling task e.g. using SketchUp tool.

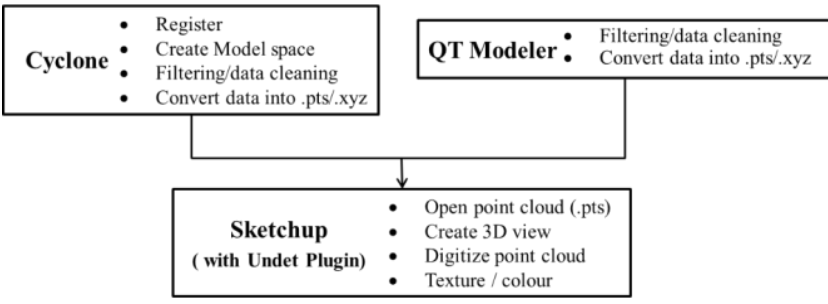

Figure 4. Simplified Method from point-clouds to 3D Modelling

SketchUp software has been utilized to digitize the model. In SketchUp (with undet plugin), data is opened and processed. Using the suitable tools to start digitizing and to insert some colours or textures for the building is important. Figure 5 shows the transformation with digitizing from point-clouds to $3 \mathrm{D}$ model.

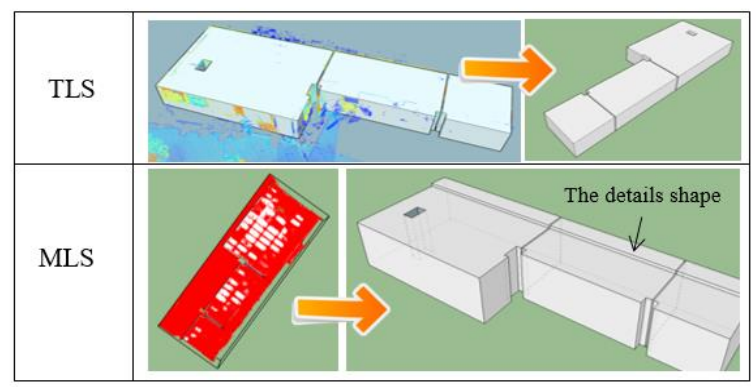

Figure 5. Point-clouds to 3D model

The 3D model developed by Indoor MLS shape shows more details with the showing of the edge at every angle compared to the TLS 3D model. This is one of the advantages using indoor MLS because the operator is moves and coverage angle to collect the features is wider.

\subsection{IndoorGML}

The 3D data is exported such as *.dat or GML (using FME software) to view in Java Indoor Editor (JIneditor) software. To use JIneditor there are several requirements needed such as using maven and java development kit. After some editing such as inserting state and transitioning, the data will be exported into IndoorGML.

\subsection{Web-based Design}

Web based is developed as a medium for the registration of data attribute and 3D model. Thus, the design will be a framework for standard XML-IndoorGML. There are two stages for developing web-based; designing user interface and designing a database.

\subsubsection{User Interface (UI) Design}

User interface (UI) is a front page for the communication between user and the system. Designing the user interface will be more efficient with a simple concept for data entry. Thus, with HTML coding the designing is used for this purpose.

There are several parts or information for data entry needed to be highlighted such as strata file, developer, share unit, accessories and others. This is important as a current requirement registration and the design also includes the 3D model as a file for submission to JUPEM.

In other part, 'Search' button is created for query function to find the $3 \mathrm{D}$ model. This query is based on the Unique Feature Identifier (UFI) as a primary key in a database.

Designing UI also prepares a space for IndoorGML viewer. Here, the user will use this function to check the model before uploading and submitting.

\subsubsection{Database Design}

Database design is a back end to the web pages which is to store the data and input from user. The database uses MySQL and PHPMyAdmin as a medium between database and webpages.

Database conceptual design uses UML for identifying the structured data. Figure 6 shows the UML for the strata purposes. This design states three superclass i.e. block, unit and indoor model. To add, each superclass has the attribute with the data type structure.

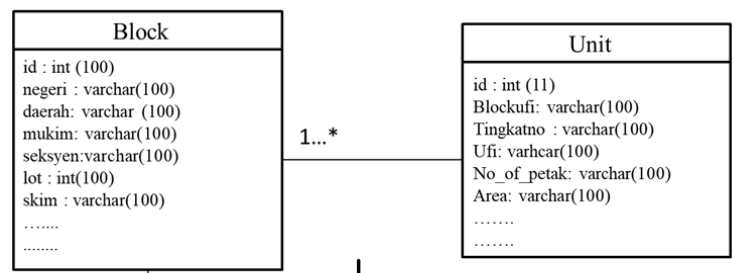

Conceptual design with UML and designing structure with PHPMyAdmin
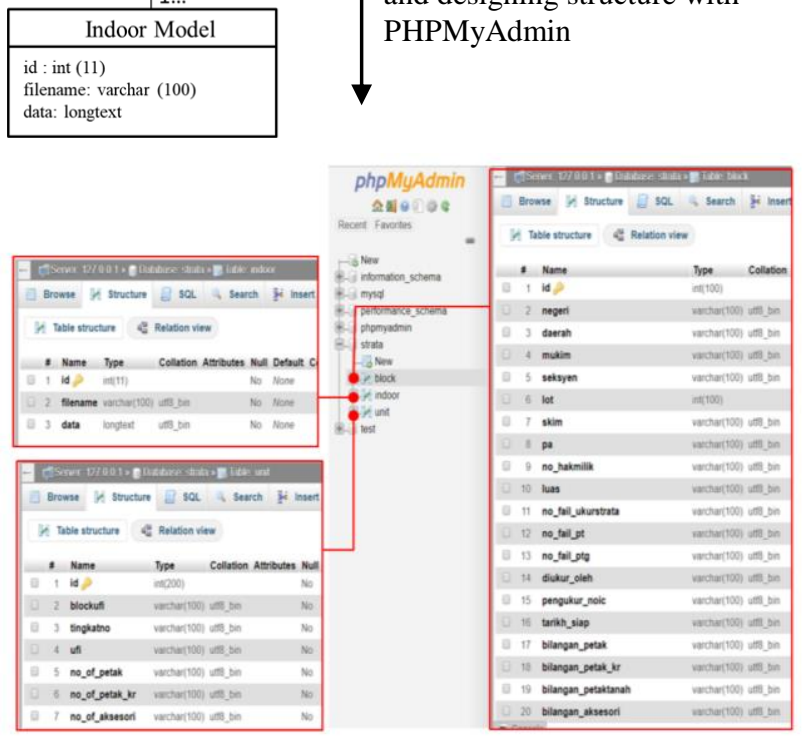

Figure 6. UML conceptual design and data structure. 


\section{INTERGRATED XML-INDOORGML}

The current XML strata schema includes block, accessories, common area, land parcel and vertical section (keratan_tegak) as items for registration. With new 3D model submission, the current schema needs to be modified to suit the 3D model with IndoorGML. Figure 7 shows the indoor features (colour) as a value added for the integrated XML-IndoorGML structured.

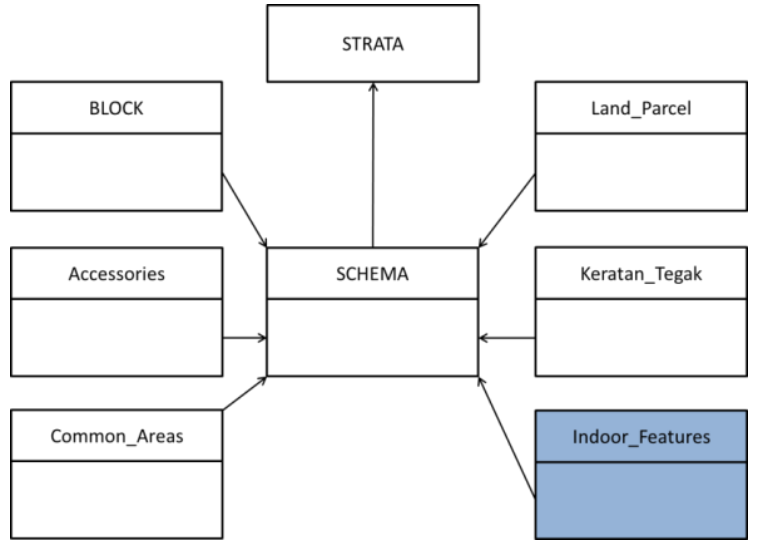

Figure 7. Schema structured integrated XML-IndoorGML

\section{CONCLUSION AND DISCUSSION}

The interface (see Figure 8) is designed using HTML with four major menus and they are about, search, form and IndoorGML. 'About' menu is the preface or introduction of the study and it consists of purpose and objectives.

'Search' menu is designed to find the model with integrated XML-IndoorGML data. The concept of 'search' menu is the same with the query function in the database. 'Form' menu for data entry is manually created by user. There are four sections for data entry such as 'strata file', 'developer', 'accessories' and the '3D model'.

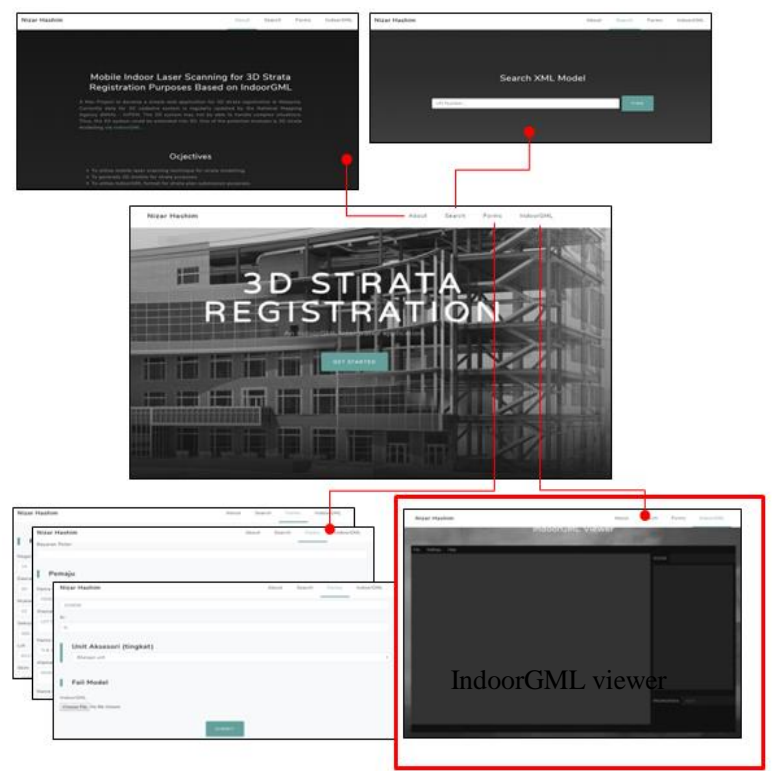

Figure 8. Web-Based user interface design
'IndoorGML' is the indoor 3D model viewer that helps the user to see a model. Another function is to make sure the right model is chosen before uploading it into the database by importing file or drag it into the viewer. The model can be viewed in the IndoorGML Viewer (see Figure 9). This viewer is an open source and can be downloaded via internet. The 3D model with wireframe view (primal) and the topology structure like node and line (duality) could be shown on the scene. With selected 'cell id' on the right column on the scene, 3D model will be highlighted. This 'cell_id' will be connected to the database to show other information of the unit.

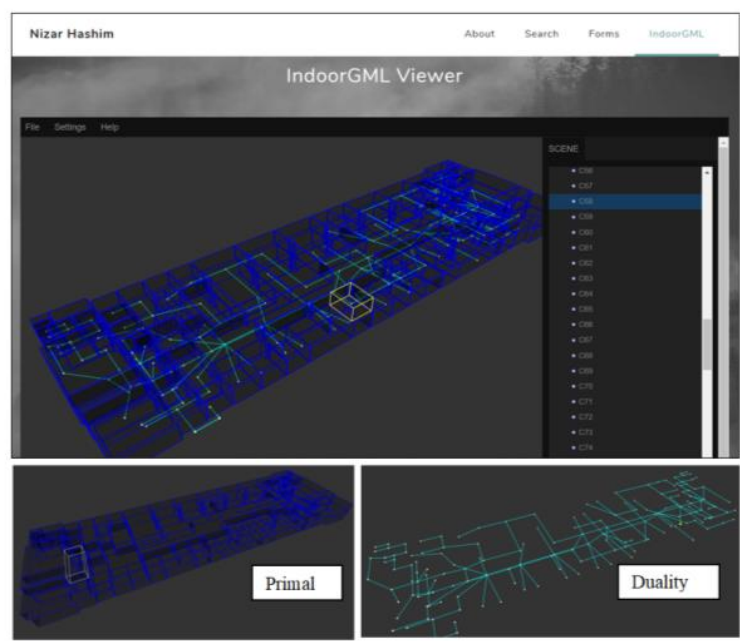

Figure 9. IndoorGML viewer

The integrated XML-IndoorGML is generated automatically after clicking 'submit' in the web pages. The non-spatial and the 3D model were linked to each other. Figure 10 shows the integrated XML-IndoorGML with non-spatial data includes 'Block', 'Aksesori', 'CommonArea', 'LandParcel' and 'KeratanTegak'. While the 3D model only contains 'IndoorFeatures',

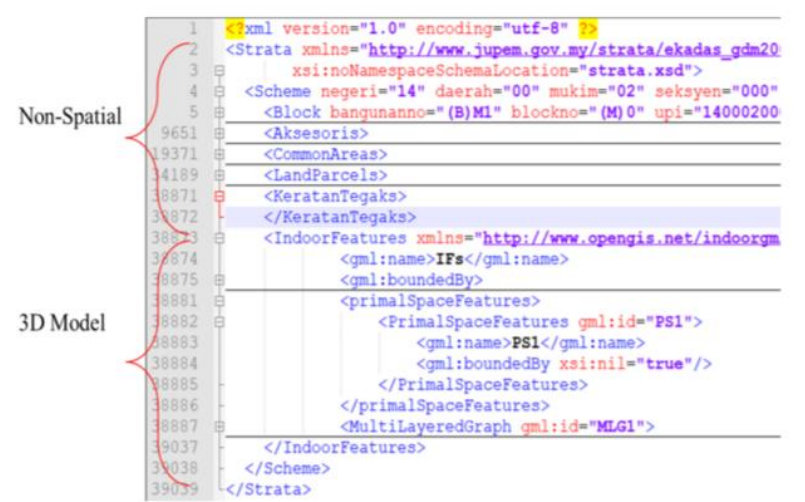

Figure 10. Integrated XML-IndoorGML

Besides, the integrated XML-IndoorGML data can be viewed via online XML viewer such as Java Script Object Notation (JSON) formatter. In this viewer, data can be uploaded for validate the XML scheme, viewed in XML Tree and managed in Beauty structures. Figure 11 shows the data has been validated by clicking the 'validate' menu and the result 'Valid XML' will appeared in right windows and the data also has been viewed in XML Tree. This structure is more significant for view in root-based layer especially to differentiate the nonspatial and 3D model scheme. 
The International Archives of the Photogrammetry, Remote Sensing and Spatial Information Sciences, Volume XLII-4/W16, 2019 6th International Conference on Geomatics and Geospatial Technology (GGT 2019), 1-3 October 2019, Kuala Lumpur, Malaysia

Besides, by clicking 'format / beauty' menu will be managed the scheme with beauty formatting structures. This structure is similar with the XML Tree but it shows data in a line format.
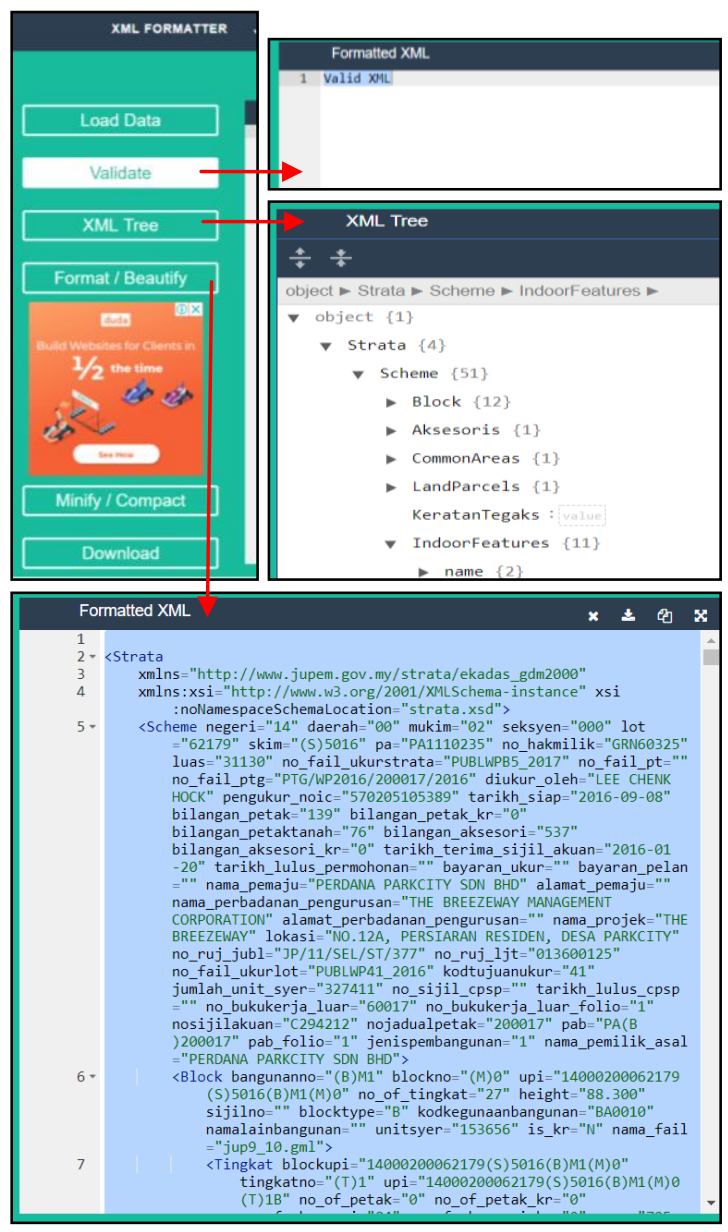

Figure 11. Integrated XML-IndoorGML

This study can be considered as first attempt in the 3D strata registration using integrated XML-IndoorGML schema. There are several aspects that need to be considered for a complete implementation of 3D strata registration. The following list of recommendations could be highlighted for future works.

(a) Automated building or rooms edge detection from laser scanned data for 3D modelling.

(b) Investigation on the party-wall issues with respect to RRRs 3D strata.

(c) Further investigation on topology for strata building.

(d) Further investigation on the potential of Web-based applications with complete database for registration to use of 3D building with actual procedures in Webbased development cycle. Development of the web viewer for integrated XMLIndoorGML with additional menu to display the attribute or information of the 3D model.

(f) Development of an ideal platform for complex strata models e.g indoor and outdoor building with LADM standard.

(g) Development of the standard for 'StrataGML' for further potential and implementation of strata purposes.

(h) Further investigation on RRRs aspect of the 3D strata.
Further research in 3D strata visualisation for Augmented Reality.

Further investigation on the potential and implementation for other applications such as buildings facilities management.

\section{REFERENCES}

Abdul-Rahman, A. (2016). 3D city modelling for Istanbul city. Keynote for international Conforence on Geomatics and Geospatial Technology (GGT) 2017, Kuala Lumpur, Malaysia.

Alattas, A., Van Oosterom, P., Zlatanova, S., Diakite, A., \& Yan, J. (2018). Developing a database for the LADMIndoorGML model. In proceeding $6^{\text {th }}$ International FIG $3 D$ cadastre workshop. Delf, Nethrlands.

Buyuksalih, G., and S. Bayburt (2017). 3D city modelling for Istanbul city. Keynote for international Conforence on Geomatics and Geospatial Technology (GGT) 2017, Kuala Lumpur, Malaysia.

Hashim, M. N., Hassan, M. I., \& Rahman, A. A. (2018). 3D Modelling Towards Strata Registration. ISPRS-International Archive of the Photogrammetry, Remote Sensing and Spatial Information Sciences, 4249, pp. 23-26.

Hassan, M.I. (2017). Conceptual Modelling of 3D Cadastre and LADM. In Cadastre:Geo-Information Innovations in Land Administration, pp. 95-111.

Ilku, K., \& Tamas, J. (2018). IndoorGML modelling: A case study. In IEEE 2018 19th International Carpathian Control Conference (ICCC) , pp. 633-638.

Isa, M.N., Chan, K. L., Hashim, M.N., Hassan, M.I., Idris, K.M and Abdul-Rahman, A., (2018). 3D Strata Modelling based on Indoor LiDAR Data (9476). In FIG Congress: Enhancing the geospatial maturity of societies. Istanbul, Turkey.

Romsek, B. R. (2008). Terrestrial laser scanning: Comparison of time-of-flight and phase based measuring systems.

\section{STA (1985). Strata Titles Act 1985.}

Tekavec, J., and Lisec, Anka. (2018). A framework for accessing cadastral data as a source for 3D indoor modelling. In proceeding 6th International FIG 3D cadastre workshop. Delf, Nethrlands.

\section{Revised August 2019}

